\title{
Online Monitoring of Electrochemical Degradation of Paracetamol through a Biomimetic Sensor
}

\author{
Mariana Calora Quintino de Oliveira, ${ }^{1}$ Marcos Roberto de Vasconcelos Lanza, ${ }^{2}$ \\ José Luis Paz Jara, ${ }^{3}$ and Maria Del Pilar Taboada Sotomayor ${ }^{1}$ \\ ${ }^{1}$ Departamento de Química Analítica, IQ, Universidade Estadual Paulista, 14801-970 Araraquara, SP, Brazil \\ ${ }^{2}$ Departamento de Química e Física Molecular, IQSC, Universidade de São Paulo, 13560-970 São Carlos, SP, Brazil \\ ${ }^{3}$ Instituto de Quimica, Universidade Estadual de Campinas, 13083-970 Campinas, SP, Brazil
}

Correspondence should be addressed to Maria Del Pilar Taboada Sotomayor, mpilar@iq.unesp.br

Received 22 February 2011; Accepted 19 March 2011

Academic Editor: Bengi Uslu

Copyright (c) 2011 Mariana Calora Quintino de Oliveira et al. This is an open access article distributed under the Creative Commons Attribution License, which permits unrestricted use, distribution, and reproduction in any medium, provided the original work is properly cited.

\begin{abstract}
This paper reports, for the first time, the online monitoring to the electrochemical degradation of the paracetamol using a biomimetic sensor coupled to a Flow Injection Analysis (FIA) system. The electrochemical degradation of the drug was carried out in aqueous medium using a flow-by reactor with a DSA anode. The process efficiency was monitored at real time by the biomimetic sensor constructed by modifying a glassy carbon electrode with a Nafion membrane doped with iron tetrapyridinoporphyrazine (FeTPyPz). Simultaneously, we carried out off-line analysis by liquid chromatography (HPLC) during the experiments in order to validate the proposed system. In addition, to investigate the degradation products of the paracetamol electrolysis, we used the techniques of UPLC/MS and GC/MS.
\end{abstract}

\section{Introduction}

The environmental sciences have an enormous progress in recent years. The need for planning the rational use of energy resources and water provided a challenge for the applied sciences and engineering to develop new technologies, new processes, and new materials for the prevention and control of pollution. This is also a consequence of the increase of legal pressure that is forcing the industry to accept responsibility for waste treatment or storage, in an attempt to minimize pollution [1].

Oxidative conventional treatments, which may be chemical or biological, of aqueous solution containing organic compounds, are often effective in enforcement. However, this action is not enough nowadays, when environmental considerations should be considered. The conventional technology for wastewater treatment requires chemical storage and handling of hazardous chemicals and leads to the generation of toxic waste. Moreover, biological treatment is time consuming and performed in large physical areas, which also leads to the generation of soluble non-biodegradable waste. In addition, compounds with high molecular weight of fractions present in some types of aqueous effluents tend to be resistant to biodegradation [2].

In this field, the electrochemical and photochemical technologies may offer an efficient way for pollution controls, providing the degradation of organic pollutants without the disadvantages observed with conventional treatments. Electrolysis, heterogeneous photocatalysis, and photoassisted electrolysis can be used as primary or additional treatment at reduction of the organic matter. In fact, electrons and photons are the unique reagents added to the treatment process that basically does not generate subproducts [3].

The electrolytic process is probably the best tool in the treatment of aqueous effluent, ideal for the present, where environmental considerations are always ahead [2].

The literature outlines the principles and mechanisms for electrochemical treatment of aqueous solutions containing organic compounds with simultaneous oxygen evolution [4, 5]. The key to efficient electrolytic treatment is strongly based 
on the choice of anodic material. The high resistance to corrosion of the anode and physical and chemical stability under high applied potentials are the main requirements for an efficient process. When the above properties are required, dimensionally stable anodes (DSAs) are the natural candidates. This designation denotes a class of electrodes thermally prepared where a titanium substrate is covered by metallic oxides. Coatings include $\mathrm{TiO}_{2}, \mathrm{IrO}_{2}, \mathrm{RuO}_{2}$, and $\mathrm{Ta}_{2} \mathrm{O}_{5}$. Combinations such as $\mathrm{TiO}_{2} / \mathrm{RuO}_{2}$ are indicated for the alkaline medium, while $\mathrm{IrO}_{2} / \mathrm{Ta}_{2} \mathrm{O}_{5}$ usually shows longer useful life in acid electrolytes. Moreover, some DSA electrodes may receive addition of $\mathrm{SnO}_{2}$ and $\mathrm{Sb}_{2} \mathrm{O}_{5}$ in concentrations ranging appropriately, aiming to increase lifetime and eventually their catalytic power and selectivity $[6,7]$. Currently, are commercialized some DSA anodes, between them is the DSA-Cl $\mathrm{Cl}_{2}$ that is composed for a mixture of $70 \%$ of $\mathrm{TiO}_{2}$ and $30 \%$ of $\mathrm{RuO}_{2}$ and was used in the electrochemical degradation of paracetamol in this work.

On the other hand, biomimetic sensors are a recent experimental strategy that has been used to get chemical sensors more stables and durable that the conventional biosensors, that are based on the use of biological materials, such as enzymes or antibodies. These devices aim at to overcome the limitations of the enzymatic biosensors such as availability, cost, and instability of enzymes as well as to promote improvement in the electronic transfer between electrode/ active site (biomimetic catalyst)/subtract, since that in the biomimetic sensors the "active site" is free, differently from in the enzymes, where the active site is surrounded by a dense layer of residual aminoacids [8, 9]. However, a condition to mimic or to choose an enzyme for the construction of biomimetic sensors is that the chemistry of the enzymatic reaction catalysis and the structure of its active site should be very well known, and in this sense the P450 enzymes are perfectly fitted in these conditions [9].

In previous papers $[10,11]$ were described the studies carried out to develop an amperometric sensor based on the use of iron tetrapyridinoporphyrazine (FeTPyPz), a biomimetic catalysts of the P450 enzyme, and its coupling and application satisfactory in the paracetamol detection in an FIA system. Due to the excellent characteristics shown by this FIA system using the biomimetic sensor as detector, and being recognized the importance of the degradation of organic compounds by means electrochemistry, this paper intends to demonstrate the viability of the use of sensors highly selective, stable, and durable, in monitoring online and in real-time of the paracetamol electrochemical degradation, as an alternative tool to existing methods for the offline monitoring, that may be time consuming, expensive, pollutants, and often not selective, as are the cases of the chemical oxygen demand and total organic carbon (TOC). Thus, this paper shows the promising junction of two areas of recent and increasing concern, the electrochemical and electroanalysis.

\section{Experimental}

2.1. Chemicals and Solutions. All chemicals used in the construction and application of the sensor were analytical

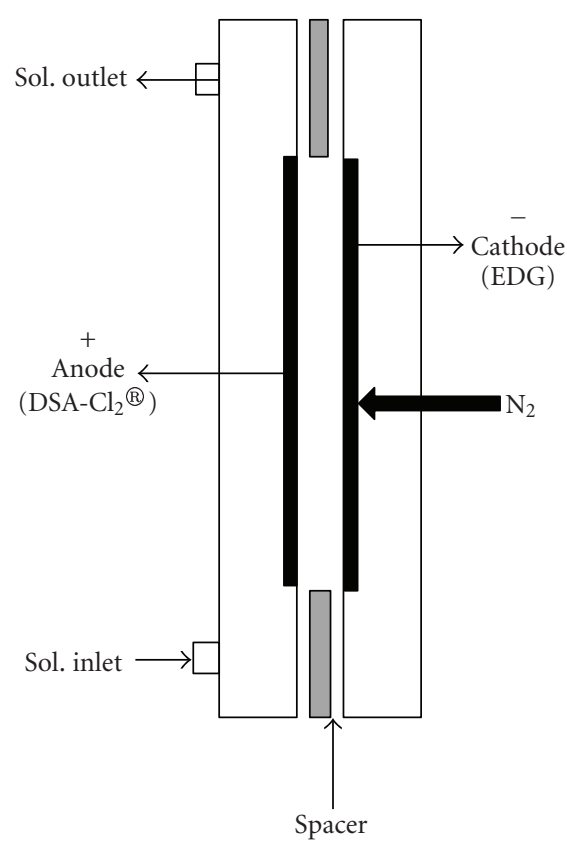

FIGURE 1: Representative scheme of the electrochemical reactor used in this work.

grade reagents. All chemicals used in the chromatographic experiments were high-performance liquid chromatography (HPLC) grade reagents. The biomimetic complex, iron (III) tetrapyridinoporphyrazine $(\mathrm{FeTPyPz})$, was prepared and purified as previously described [12]. Acetic acid and N,Ndimethylformamide (DMF) were acquired from Synth (São Paulo, Brazil). Paracetamol (acetaminophen) was obtained from Sigma (St. Louis, USA). 5\% (m/v) Nafion solution was from Aldrich (Milwaukee, USA). Sodium acetate was acquired from Merck (Darmstadt, Germany), and all HPLC grade solvents were from Tedia (Rio de Janeiro, Brazil). Paracetamol and acetate buffer solutions were prepared with water purified in a Millipore Milli-Q system, and the $\mathrm{pH}$ was determined using Thermo Scientific $\mathrm{pH}$-meter (Orion 3 Star, Benchtop).

2.2. Electroanalytical Flow System. The biomimetic sensor was constructed as previously described [10, 11]. First, a solution containing $5 \mathrm{mg} \mathrm{mL}^{-1}$ of the FeTPyPz in DMF was prepared. Then, the surface of a glassy carbon (GC) electrode (Metrohm, Switzerland), with a geometrical area of $0.126 \mathrm{~cm}^{2}$, was cleaned according to the procedure described in the literature [13]. After cleaning the electrode, $100 \mu \mathrm{L}$ of FeTPyPz solution was mixed with $50 \mu \mathrm{L}$ of $5 \%(\mathrm{~m} / \mathrm{v})$ Nafion solution, and an aliquot of $50 \mu \mathrm{L}$ of this mixture was placed on the surface of the electrode. Finally, the solvent was evaporated at room temperature during 6 hours, forming a thin green film.

The biomimetic sensor was inserted into a flow-through wall-jet amperometric cell and used as the working electrode (WE in Figure 2). An $\mathrm{Ag} \mid \mathrm{AgCl}$ (KClsat) electrode was the reference (RE), and a platinum wire was the auxiliary electrode (AE). The electrodes were connected to a potentiostat (Palm-sense, Palm Instruments BV, The Netherlands) 


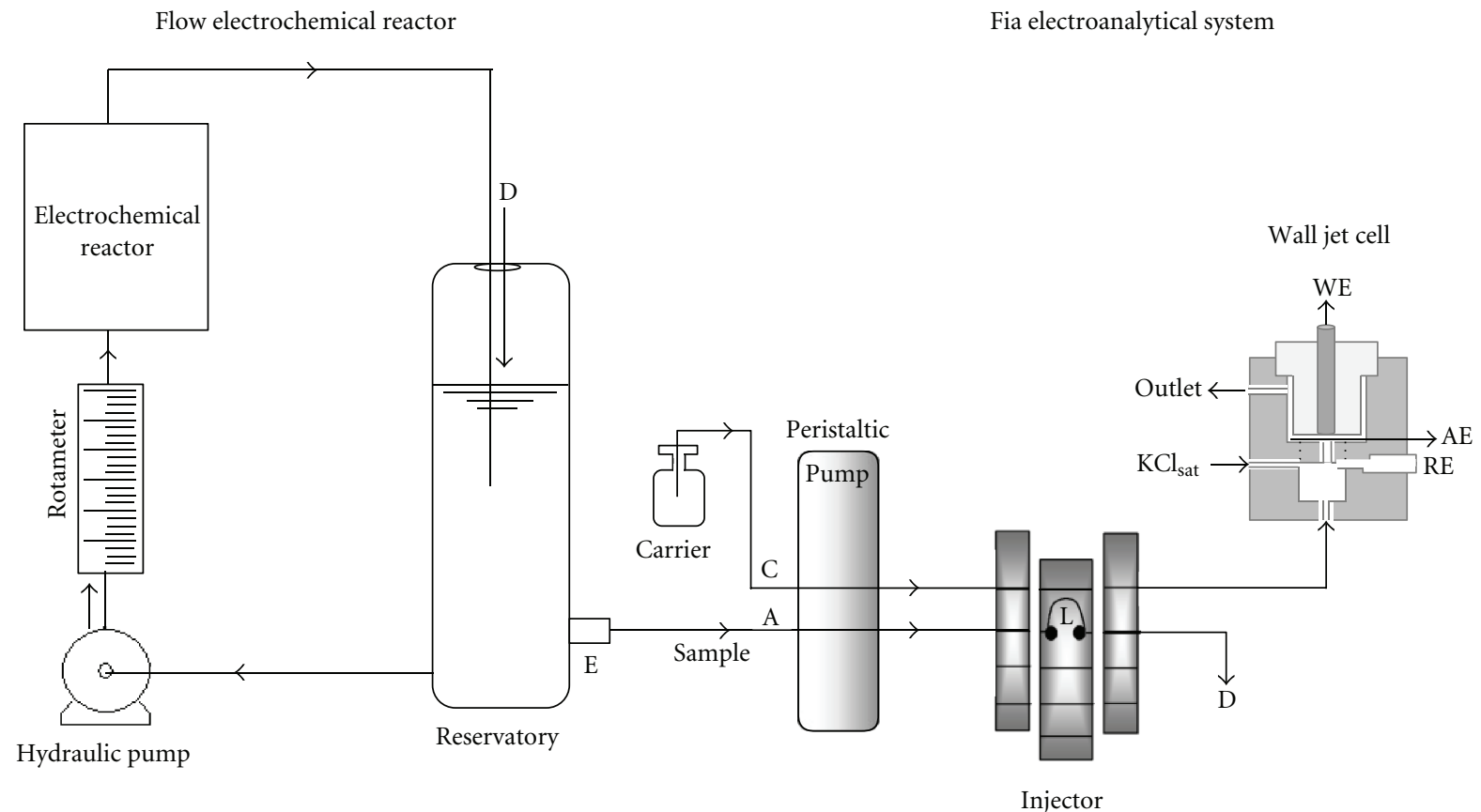

FIGURE 2: Scheme of the coupling of the reactor with the FIA system. WE is the biomimetic sensor, AE represents the counter electrode, $\mathrm{RE}$ is the reference electrode. The $\mathrm{D}$ channel is used for the return of the electrolysis solution (sample) from the injector to the reservoir of the reactor, allowing maintain-sink condition in the experiments without loss of volume and thus avoiding errors in the calculation of the concentration of paracetamol, since the injected volume is only $75 \mu \mathrm{L}$ in each sampling.

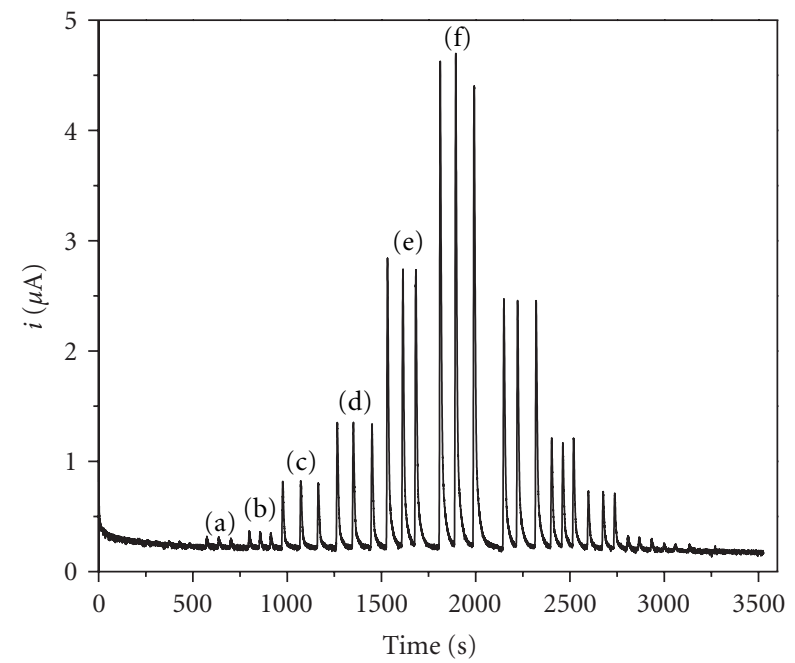

FIGURE 3: FIA signals obtained using the electrolyte solution as carrier stream, consisting of $0.1 \mathrm{~mol} \mathrm{~L}^{-1} \mathrm{~K}_{2} \mathrm{SO}_{4}$ and $5.0 \times$ $0^{-4} \mathrm{~mol} \mathrm{~L}^{-1} \mathrm{FeSO}_{4} \cdot 7 \mathrm{H}_{2} \mathrm{O}$. The concentrations evaluated were: (a) $5.0 \times 10^{-5} \mathrm{~mol} \mathrm{~L}^{-1}$ (b) $5.0 \times 10^{-4} \mathrm{~mol} \mathrm{~L}^{-1}$ (c) $1.0 \times 10^{-3} \mathrm{~mol} \mathrm{~L}^{-1}$; (d) $1.0 \times 10^{-2} \mathrm{~mol} \mathrm{~L}^{-1}$ (e) $2.5 \times 10^{-2} \mathrm{~mol} \mathrm{~L}^{-1}$ and (f) $5.0 \times$ $10^{-2} \mathrm{~mol} \mathrm{~L}^{-1}$.

interfaced to a microcomputer for potential control and data acquisition.

A peristaltic pump (Ismatec) was used to provide the flow of the $0.1 \mathrm{~mol} \mathrm{~L}^{-1} \mathrm{~K}_{2} \mathrm{SO}_{4}$ and $5.0 \times 10^{-4} \mathrm{~mol} \mathrm{~L}^{-1} \mathrm{FeSO}_{4}$. $7 \mathrm{H}_{2} \mathrm{O}$ carrier solution at $1.25 \mathrm{~mL} \mathrm{~min}^{-1}$. The standards and samples containing paracetamol were injected $($ loop $=75 \mu \mathrm{L})$ into the carrier using a sliding central bar sampling valve (injector) [14].

2.3. Electrochemical Degradation System. To carry out the electrolysis, was used a flow-by electrochemical reactor with a compartment constructed with PVC plates mounted in the form of a filter press, designed to be coupled to a reservoir with a capacity of $2.5 \mathrm{~L}[15,16]$. The reactor used a gas diffusion electrode (GDE) containing 20\% (w/w) polytetrafluoroethylene (PTFE) acting as a carbon cathode with geometric area of $20 \mathrm{~cm}^{2}$ and a commercial anode of DSA-Cl ${ }_{2}$ by De Nora do Brazil Ltda [17] (with a geometrical area of $20 \mathrm{~cm}^{2}$ ). Between the two PVC plates, anodic and cathodic, was placed a rubber spacer, providing a distance of $3 \mathrm{~mm}$, allowing the passage of the solution (Figure 1). The reactor was connected to a recirculation system consisting of a reservoir, a hydraulic pump, and a rotameter to measure the flow of solution in the system (Figure 2). In all experiments, the reactor system operated in the recirculation mode.

To perform the electrochemical degradation of paracetamol was used the electrolysis at constant current through the coupling of a power supply (Tectrol TC 20-05) to the electrochemical reactor system. In this work were used the current densities of 5 and $100 \mathrm{~mA} \mathrm{~cm}^{-2}$. The flow of the degradation system was set at $50 \mathrm{Lh}^{-1}$ which presents a laminar regime (Reynolds number) of approximately 500. The electrolyte volume was $2.0 \mathrm{~L}$, consisting of $0.1 \mathrm{~mol} \mathrm{~L}^{-1} \mathrm{~K}_{2} \mathrm{SO}_{4}$ and $5.0 \times 10^{-4} \mathrm{~mol} \mathrm{~L}^{-1} \mathrm{FeSO}_{4} \cdot 7 \mathrm{H}_{2} \mathrm{O}$ containing $2041.2 \mathrm{mg} \mathrm{L}^{-1}$ $\left(1.35 \times 10^{-2} \mathrm{~mol} \mathrm{~L}^{-1}\right)$ of paracetamol. In all tests was applied a positive flow of $\mathrm{N}_{2}(0.2 \mathrm{bar})$ to GDE by means of the external chamber of the cathode in order to avoid the 
formation of $\mathrm{H}_{2} \mathrm{O}_{2}$ from the cathodic reaction of $\mathrm{O}_{2}$, and that could affect the sensor response [18].

\subsection{On-Line Monitoring System: FIA and Reactor Coupling.} The FIA/sensor system was coupled to the electrochemical system of degradation (Figure 2), by the reservoir, precisely in the region of sampling of the reactor (E in Figure 2), where the aliquots are usually collected to perform the analyzes of monitoring via off-line. The electrochemical degradation system was refrigerated to maintain a constant temperature at $25^{\circ} \mathrm{C}$. Figure 2 shows the diagram of the coupling of the two systems, electrochemical and electroanalytical for the monitoring on-line and at real-time of the paracetamol degradation. The solution/sample from the flow-by electrochemical reactor was injected directly into the analytical system via the sample valve at time intervals pre-established. Prior to filling the sampling loop $(75 \mu \mathrm{L})$ trapping-bubbles had to be inserted into system to prevent the large number of bubbles formed during the degradation process to entering in the FIA system, which would harm the measurements repeatability. This solution, which leaves the degradation system, travels through the FIA system passing by the injector until it reaches the wall jet cell, where it enters into contact with the biomimetic sensor selective for paracetamol, where are performed amperometric measurements, which is the electroanalytical technique, used to register the FIAgrams. The analyte that is not injected into the electrochemical cell returns to the degradation system by means of the $\mathrm{D}$ channel (Figure 2). Thus, keeping a continuous flow of analyte is possible to determine at real-time the amount to paracetamol which is degraded over time.

2.5. HPLC Measurements. In order to validate the results obtained using the proposed on-line system, they were compared to those obtained using the official chromatographic method based on HPLC [19]. Chromatographic analyses were performed using a Shimadzu Model 20A liquid chromatograph coupled to a UV/V detector (SPD-20A), autosampler (SIL-20A), and a degasser DGU-20A5, controlled by a personal computer. A C18 column $(250 \times$ $4.6 \mathrm{~mm}$, Shim- Pack CLC-ODS) was used, inside an oven (Shimadzu CTO-10AS) maintained at $30^{\circ} \mathrm{C}$. The mobile phase was a mixture of methanol and water in a ratio of 13:87 (v/v) with apparent $\mathrm{pH}$ of 4.9. The flow rate was $1.0 \mathrm{~mL} \mathrm{~min}^{-1}$, the sample injection volume $20 \mu \mathrm{L}$, and the detector absorption wavelength $254 \mathrm{~nm}$.

The analytical curve was constructed under the same conditions of the degradation. For this, were prepared standard solutions of paracetamol in the electrolyte of degradation $\left(0.1 \mathrm{~mol} \mathrm{~L}^{-1} \mathrm{~K}_{2} \mathrm{SO}_{4}\right.$ and $5.0 \times$ $\left.10^{-4} \mathrm{~mol} \mathrm{~L}^{-1} \mathrm{FeSO}_{4} \cdot 7 \mathrm{H}_{2} \mathrm{O}\right)$ contained between $1.0 \times$ $10^{-4} \mathrm{~mol} \mathrm{~L}^{-1} \quad\left(15.2 \mathrm{mg} \mathrm{mL}^{-1}\right)$ and $5.0 \times 10^{-2} \mathrm{~mol} \mathrm{~L}^{-1}$ $\left(7560 \mathrm{mg} \mathrm{mL}^{-1}\right)$. The equation of the analytical curve was used to calculate the concentration in the samples collected from the electrochemical reactor at different pre-established times of electrolysis.

The samples were collected from the reactor at the same periods of sampling realized in the on-line system and immediately frozen until the realization of the chromatographic experiments. Samples collected from degradation at $5 \mathrm{~mA} \mathrm{~cm}^{-2}$ were analyzed by HPLC two days after the electrolysis, and the samples at $100 \mathrm{~mA} \mathrm{~cm}^{-2}$ were examined five days after the electrolysis, becoming an obvious disadvantage of this method.

2.6. UPLC/MS Measurements. For these studies, aliquots of the degradation using the DSA-Cl $\mathrm{Cl}_{2}$ electrode were collected at $0,30,60$, and 90 minutes and were immediately analyzed on a Waters UltraAcquity chromatograph, equipped with a binary pump, a C18 reversed phase column Acquity UPLC$\mathrm{BEH}(2.1 \times 50 \mathrm{~mm}$ and $1.7 \mu \mathrm{m}$ particle size $)$ maintained at $37^{\circ} \mathrm{C}$, and a degasser.

Previously, in order to obtain the highest signal and the lowest retention time, the UPLC/MS conditions were optimized. For this, firstly was optimized the ionization process (conversion of the analyte in solution to the gas phase directly in the ionization source), which should preferably take place without occurring of fragmentation, in order to obtain information on the molar mass of the compounds analyzed. Thus, was carried out the direct injection of $500 \mu \mathrm{L}$ of solution of paracetamol in the electrospray source at a flow rate of $20 \mu \mathrm{L} \mathrm{min}^{-1}$. Additionally, the following chromatographic conditions were also optimized, in order to obtain the best process of separation with the lowest retention time the flow rate and mobile phase in the gradient mode.

Thus, with all parameters optimized the chromatographic analysis was performed at $0.350 \mathrm{~mL} \mathrm{~min}^{-1}$ in the gradient mode, using different mixtures of $0.1 \%(\mathrm{v} / \mathrm{v})$ formic acid in water (solvent $\mathrm{A}$ ) and $0.1 \%(\mathrm{v} / \mathrm{v})$ formic acid in acetonitrile (solvent $\mathrm{B}$ ), with the programation described follow as: initially between 0 and $4 \mathrm{~min}, 70 \%$ (a) and 30\% (b); 4-6 $\mathrm{min}, 30 \%$ (a) and 70\% (b); and in last minute (6-7 $\mathrm{min}$ ) 95\% (a) and 5\% until reaching the initial proportions of 70\% (a) and 30\% (b), respectively. Although the chromatographic run was performed for 7 minutes, in order to explore a long period of time and check if other substances would be generated during the electrolysis of paracetamol, the only peaks appeared during the first minute of running, as will be shown in Figure 7.

Additionally, the experimental conditions of the mass detector were as follows: (i) polarity: positive, ES + mode; (ii) capillarity to $1.00 \mathrm{kV}$; (iii) cone voltage: $30 \mathrm{~V}$; (iv) supply temperature: $120^{\circ} \mathrm{C}$; (v) desolvation temperature: $350^{\circ} \mathrm{C}$; (v) Gas used in the cone and desolvation: $\mathrm{N}_{2}$ and the gas flow on the cone: $100 \mathrm{~L} \mathrm{Hr}^{-1}$; (vi) desolvation gas flow $800 \mathrm{~L} \mathrm{Hr}^{-1}$; and (vii) photomultiplier voltage: $650 \mathrm{~V}$.

For analysis of the degradation samples, they were diluted 500 times, in order to avoid saturation of the detector. In the case of the sample collected before starting the electrolysis $\left(t_{o}\right)$, the initial concentration was $4.08 \mu \mathrm{g} \mathrm{mL}^{-1}$. The concentration of standard solution of paracetamol was $1.0 \mu \mathrm{g} \mathrm{mL} L^{-1}$.

2.7. GC/MS Measurements. For these studies, aliquots of the degradation at 0,30 , and 60 minutes of electrolysis 


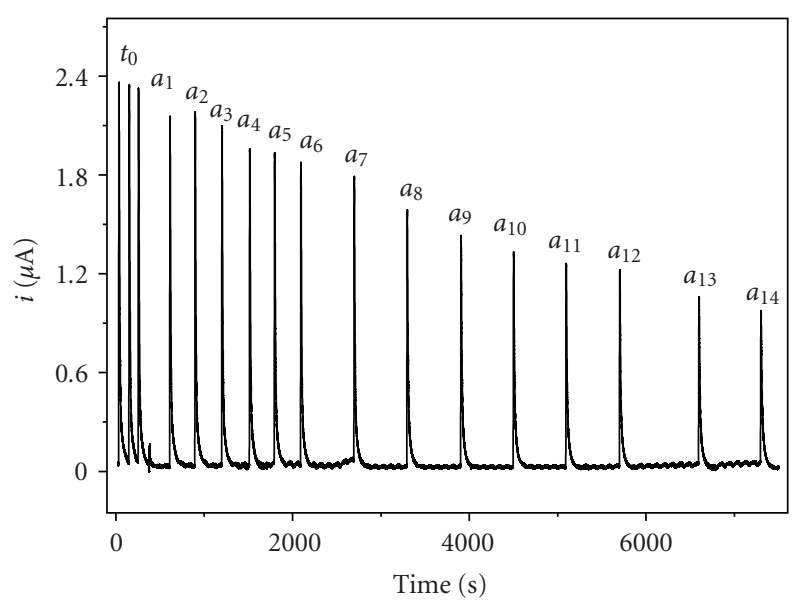

(a)

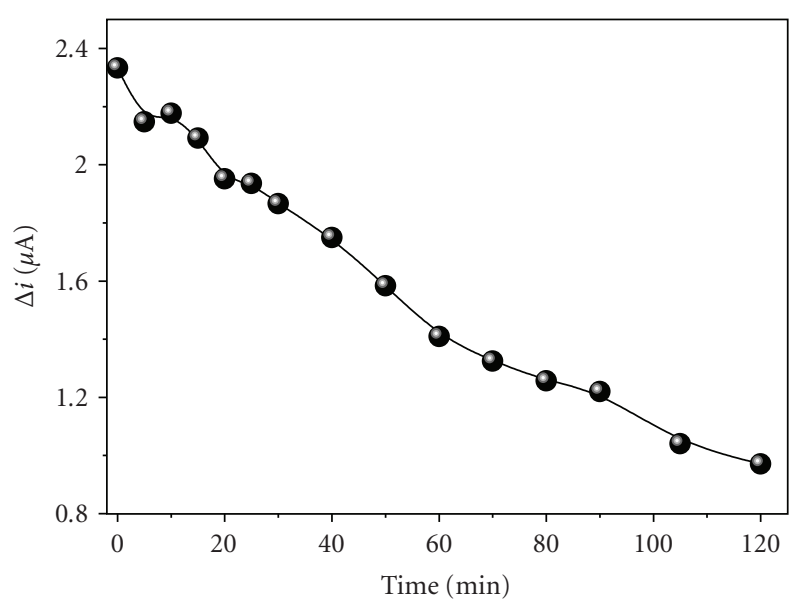

(b)

FIGURE 4: (a) Signals obtained at real-time as a function of the degradation time. $t_{0}$ : no current is applied. $a_{1}-a_{6}$ : samples injected every 5 min; $a_{7}-a_{12}$ : aliquots of samples injected at 40,50,60, 70, 80, and 90 minutes after the electrolysis; $a_{13}$ and $a_{14}$ : aliquots injected at 105 and 120 minutes of electrolysis, respectively. [Paracetamol] $]_{0}=1.35 \times 10^{-2} \mathrm{~mol} \mathrm{~L}^{-1}\left(2041.2 \mathrm{~mol} \mathrm{~L}^{-1}\right)$. (b) Response profile at real-time for the electrochemical degradation of paracetamol.

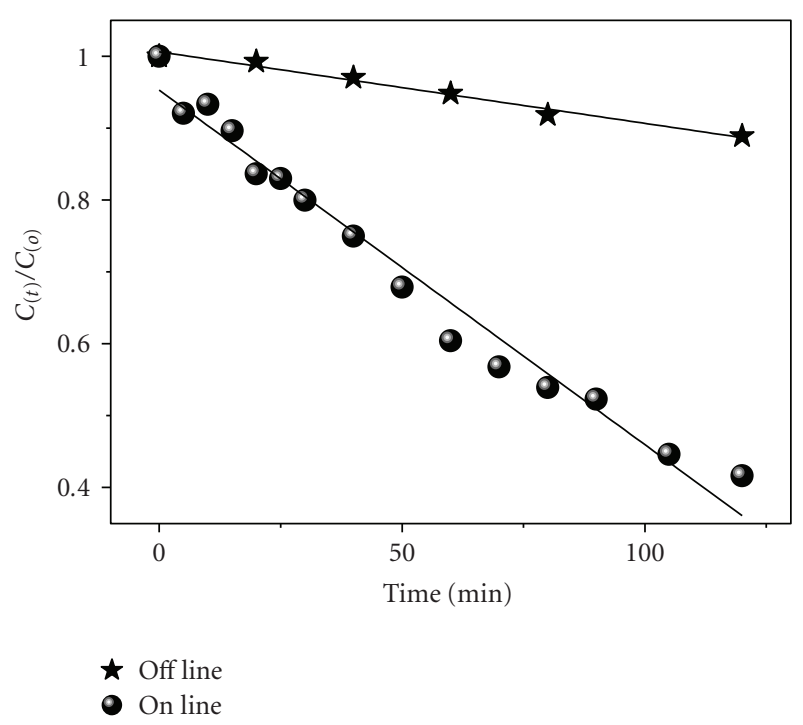

Figure 5: Profile from the decay of the concentration of paracetamol obtained by the standard HPLC method (off-line) and by the on-line system proposed, as a function of the electrolysis time. Electrolysis was conducted by applying $100 \mathrm{~mA} \mathrm{~cm}^{-2}$ using $2.0 \mathrm{~L}$ of electrolyte solution of $0.1 \mathrm{~mol} \mathrm{~L}^{-1} \mathrm{~K}_{2} \mathrm{SO}_{4}$ and $5.0 \times$ $10^{-4} \mathrm{~mol} \mathrm{~L}^{-1} \mathrm{FeSO}_{4} \cdot 7 \mathrm{H}_{2} \mathrm{O}$ containing $1.35 \times 10^{-2} \mathrm{~mol} \mathrm{~L}^{-1}$ paracetamol.

were taken from the reactor and after a process of liquidliquid extraction were analyzed by a gas chromatograph model CP-3800 Varian coupled to an ion trap mass spectrometer Varian model Saturn $2100 \mathrm{D}$ and using a column of $30 \mathrm{~m} \times 0.25 \mathrm{~mm} \times 0.25 \mu \mathrm{m}$, whose stationary phase consisted to a mixture to diphenyl (5\%)-dimethyl (95\%)polysiloxane (CP-Sil CB8, Low Bleed).

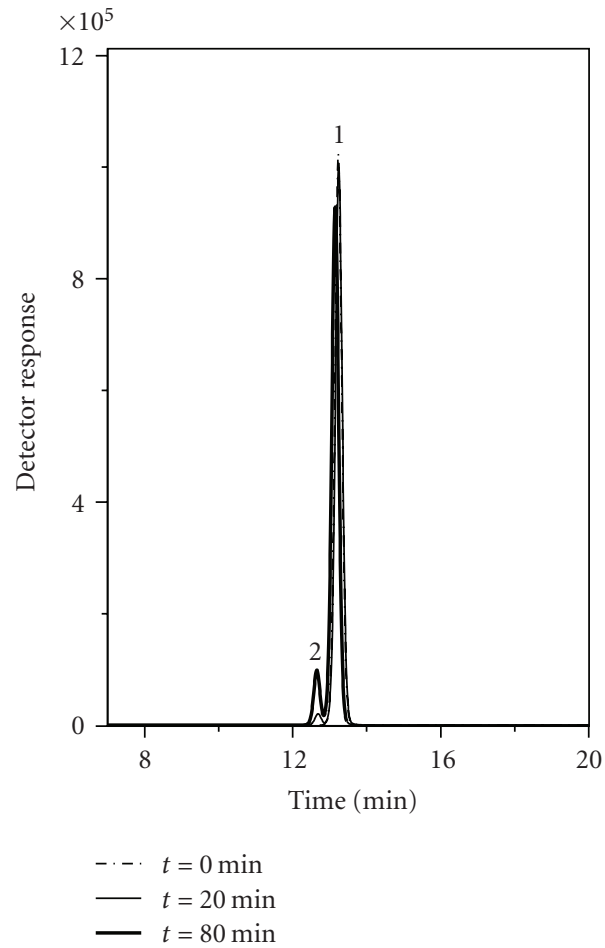

FIgURE 6: HPLC chromatograms obtained from samples of degradation of paracetamol collected at different times.

The experimental conditions were as follows: (i) injector at $260^{\circ} \mathrm{C}$ in split mode of $1: 25$ and flow of $1.0 \mathrm{~mL} \mathrm{~min}^{-1}$; and (ii) Programation of the oven: $80^{\circ} \mathrm{C}$ (1.0 minutes), ramp heating $10^{\circ} \mathrm{C} \mathrm{min}^{-1}$ up to $280^{\circ} \mathrm{C}$, and maintained at that temperature for 5 minutes. Total time to run: 26 minutes. (iii) Detector: Ion Trap MS type, $70 \mathrm{eV}$, solvent delay $2.5 \mathrm{~min}$, scan range $40-450 \mathrm{Da}$. 


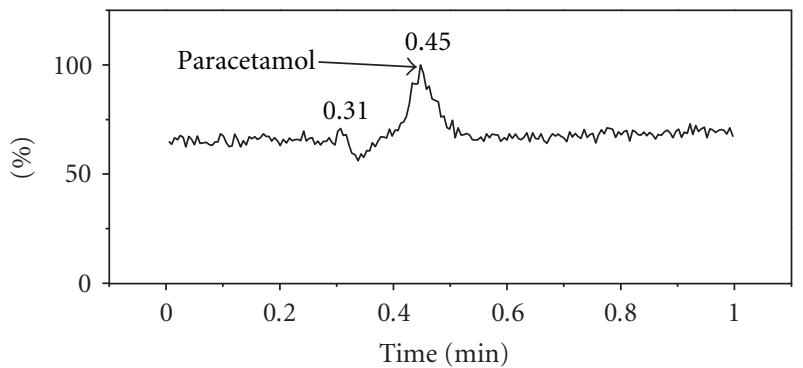

(a)

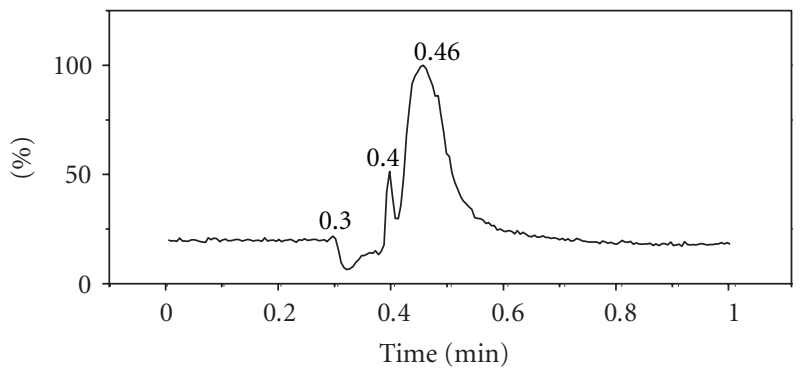

(c)

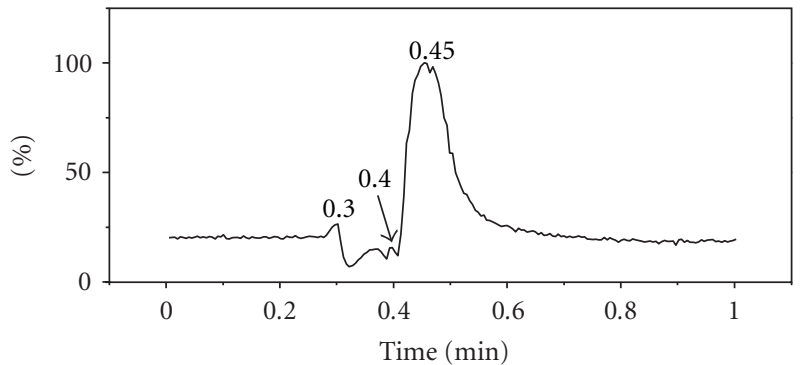

(b)

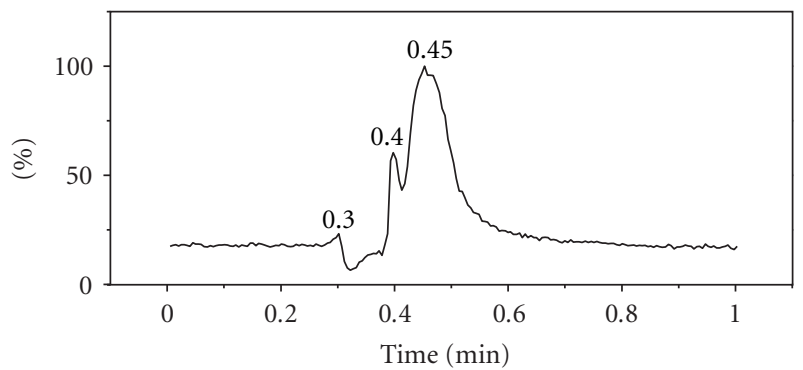

(d)

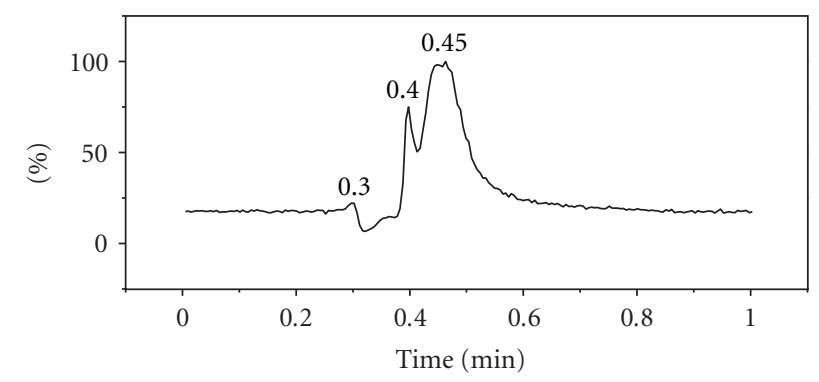

(e)

FIgURE 7: UPLC chromatograms obtained for (a) a standard solution of $0.1 \mathrm{mg} \mathrm{mL}^{-1}$ paracetamol, and for samples collected from the electrochemical reactor at (b) 0, (c) 30, (d) 60, and (e) 90 minutes.

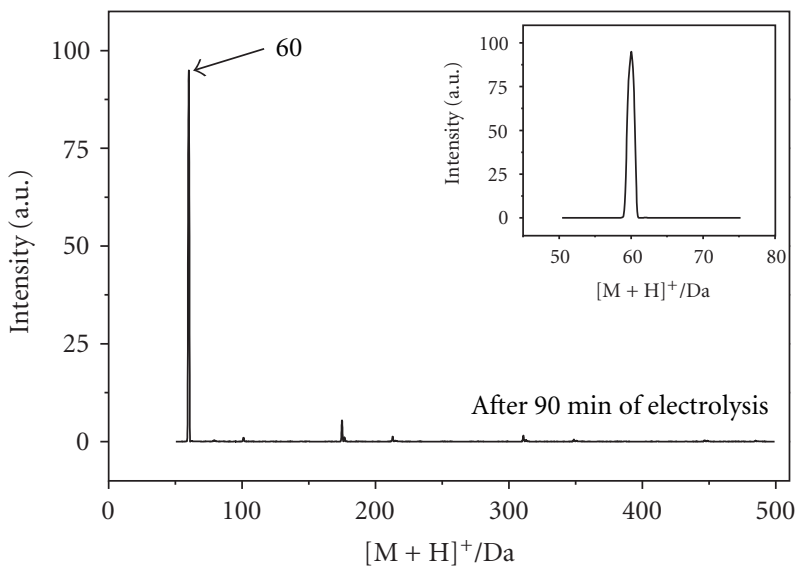

(a)

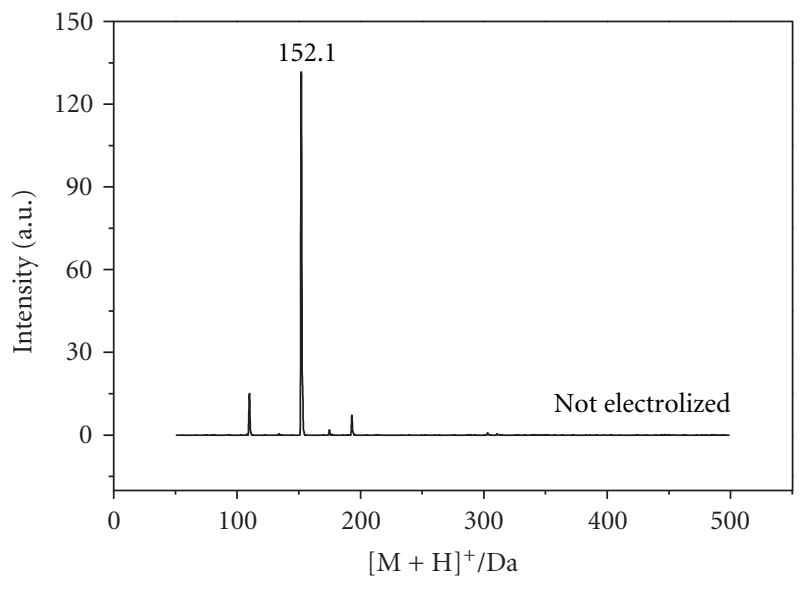

(b)

Figure 8: (a) Mass spectrum of the UPLC chromatographic peak corresponding to the retention time of 0.40 minutes in Figure 7(e). The inset shows a better view of the value of the $[\mathrm{M}+\mathrm{H}]^{+}$, which suggests that the compound is acetamide. (b) Mass spectra of the UPLC chromatographic peak at retention time of $0.45 \mathrm{~min}$, corresponding to paracetamol for samples collected before the electrolysis. 
For the analysis by GC/MS the samples were extracted in $500 \mu \mathrm{L}$ of dichloromethane. For each sample, six successive extractions were performed to each aqueous extract in an Eppendorf of $2 \mathrm{~mL}$. After the extraction performed, the organic phase was dried with $\mathrm{MgSO}_{4}$ and then injected $0.6 \mu \mathrm{L}$ into equipment. For comparative studies was prepared a solution of paracetamol in dichloromethane $\left(0.2 \mathrm{mg} \mathrm{mL}^{-1}\right)$ and injected $0.6 \mu \mathrm{L}$ into equipment.

\section{Results and Discussion}

3.1. Analytical Profile of the FIA/Sensor System. Firstly, before coupling the sensor to the system of electrochemical degradation, the analytical conditions had to be adjusted in order to obtain results more reliable and reproducible, since in this case the samples from the electrochemical reactor were in $0.1 \mathrm{~mol} \mathrm{~L}^{-1} \mathrm{~K}_{2} \mathrm{SO}_{4}$ and $5.0 \times 10^{-4} \mathrm{~mol} \mathrm{~L}^{-1} \mathrm{FeSO}_{4} \cdot 7 \mathrm{H}_{2} \mathrm{O}$ (degradation electrolyte). In this way, was evaluated the response of the system FIA/sensor in this electrolyte, and thus to continue with the studies of the on line coupling of the electrochemical and electroanalytical systems. The results obtained are shown in Figure 3, in which are present the FIA signals as a function of paracetamol concentration using the degradation electrolyte like carrier solution.

Although the sensitivity of the system has decreased when compared to the optimized FIA system, that uses $0.1 \mathrm{~mol} \mathrm{~L}^{-1}$ acetate buffer at $\mathrm{pH} 3.6$ as carrier [12], the response of the FIA/sensor system under this new adjusted condition was also reproducible and sufficiently sensitive for this application proposed. The data presented in Figure 3 were linearly adjusted to a straight line, whose linear regression, in direction of increasing concentration, is shown in (1):

$$
\begin{aligned}
\Delta i(\mu A)= & 0.03( \pm 0.01) \\
& +111.6( \pm 2.1)[\text { Paracetamol }]\left(\mathrm{mol} \mathrm{L}^{-1}\right)
\end{aligned}
$$

3.2. The Paracetamol Degradation Used a Flow-By Electrochemical Reactor. The degradation of paracetamol in the electrochemical reactor is based on the oxidation process of the drug on the surface of the anode DSA-Cl 2 . The use of a GDE as cathode aimed to compose the electric circuit in the reactor without interference in the process of degradation of the organic matter present in the electrolyte.

In this work was carried out electrolysis at current densities at two extreme values ( 5 and $100 \mathrm{~mA} \mathrm{~cm}^{-2}$ ) using as electrolyte the solution of $\mathrm{K}_{2} \mathrm{SO}_{4} 0.1 \mathrm{~mol} \mathrm{~L}^{-1}$ and $\mathrm{FeSO}_{4} \cdot 7 \mathrm{H}_{2} \mathrm{O}$ $5.0 \times 10^{-4} \mathrm{~mol} \mathrm{~L}^{-1}$, aiming to allow the complete oxidation of the paracetamol.

The results obtained at $5 \mathrm{~mA} \mathrm{~cm}^{-2}$ practically does not present significant variation of the paracetamol concentration after the first 20 minutes of the electrochemical degradation begin, monitored via FIA/sensor and HPLC (Table 1). On the other hand, as expected, results more relevant were obtained when was applied a current density of $100 \mathrm{~mA} \mathrm{~cm}^{-2}$, and in this work will be presented the results obtained in this condition.
TABLe 1: Values of the concentration of paracetamol in the electrochemical degradation with $\mathrm{DSA}-\mathrm{Cl}_{2}$ anode at $5 \mathrm{~A} \mathrm{~cm}^{-2}$, obtained through the method FIA with amperometric detector (biomimetic sensor) and chromatography (reference).

\begin{tabular}{lcc}
\hline \multirow{2}{*}{ Electrolysis time/min } & \multicolumn{2}{c}{$[$ Paracetamol $] / \mathrm{mol} \mathrm{L}^{-1}$} \\
& FIA/sensor & HPLC \\
\hline 0 & 0.0135 & 0.0135 \\
20 & 0.0094 & 0.0131 \\
40 & 0.0089 & 0.0132 \\
60 & 0.0095 & 0.0130 \\
80 & 0.0090 & 0.0124 \\
90 & 0.0088 & n.a. \\
120 & 0.0097 & 0.0125 \\
\hline
\end{tabular}

n.a.: not analyzed.

3.3. Coupling of FIA/Sensor to the Flow-By Electrochemical Reactor. To evaluate the performance of the flow injection system with biomimetic detection in the on-line monitoring of the paracetamol degradation performed in an electrochemical reactor at pilot scale, both systems were coupled as described in Section 2.4 (Figure 2).

In this case, the measurements were performed injected directly into the FIA system (flow rate of $1.25 \mathrm{~mL} \mathrm{~min}^{-1}$ ) $75 \mu \mathrm{L}$ of the solution/sample from the electrochemical degradation system. Figure 4(a) shows the signals obtained at real-time by the FIA system for the paracetamol degradation at $100 \mathrm{~A} \mathrm{~cm}^{-2}$. Figure 4(b) shows the corresponding graph of the current variation $(\Delta i)$ at function of time. The three initial injections correspond to the signals obtained before the start of electrolysis $\left(t_{o}\right)$ and served to verify the stability of the on-line system. With the data shown in Figure 4(b) and using (1), we could verify that the graph $\ln$ [Paracetamol] versus time shows a linear adjustment $(R=0.9963, n=$ 15) whose equation is given as follows (2), suggesting that the kinetics of electrochemical degradation of paracetamol follows a behavior of pseudo-first order [20]:

$$
\ln [\text { Paracetamol }]=-4.32-7.4 \times 10^{-3} / \mathrm{min}^{-1} .
$$

In (2) it is verified that the linear coefficient corresponds to $\ln [\text { Paracetamol }]_{0}$ providing the value of $0.0133 \mathrm{~mol} \mathrm{~L}^{-1}$ of paracetamol, initially added in the electrochemical reactor. The slope corresponds to an apparent constant of the pseudo-first order of $7.4 \mathrm{~min}^{-1}$. A great advantage of this proposed on-line system is that a great number of points can be monitored in comparison with the chromatographic off-line method, and thus all constants found for the electrochemical degradation will be more accurate, because they will be based on a larger number of data.

3.4. Quantification of Paracetamol Employed the Official Method of Analysis (Off-Line) in the Electrolysis Performed in the Flow-By Electrochemical Reactor. Analyzes were performed to quantify paracetamol using the official method of analysis based on high-performance liquid chromatography (HPLC), with the purpose of comparing the results obtained 


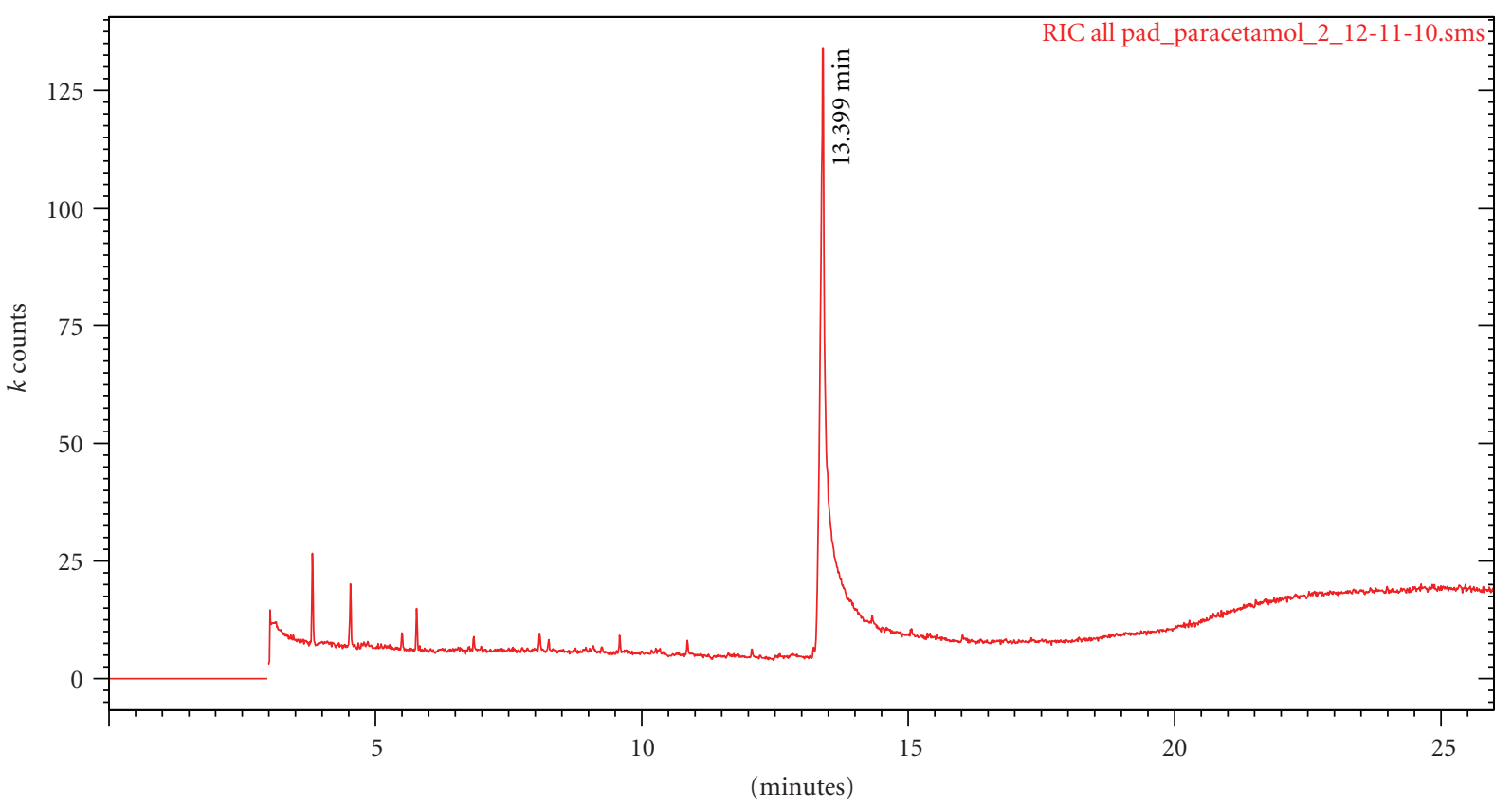

(a)

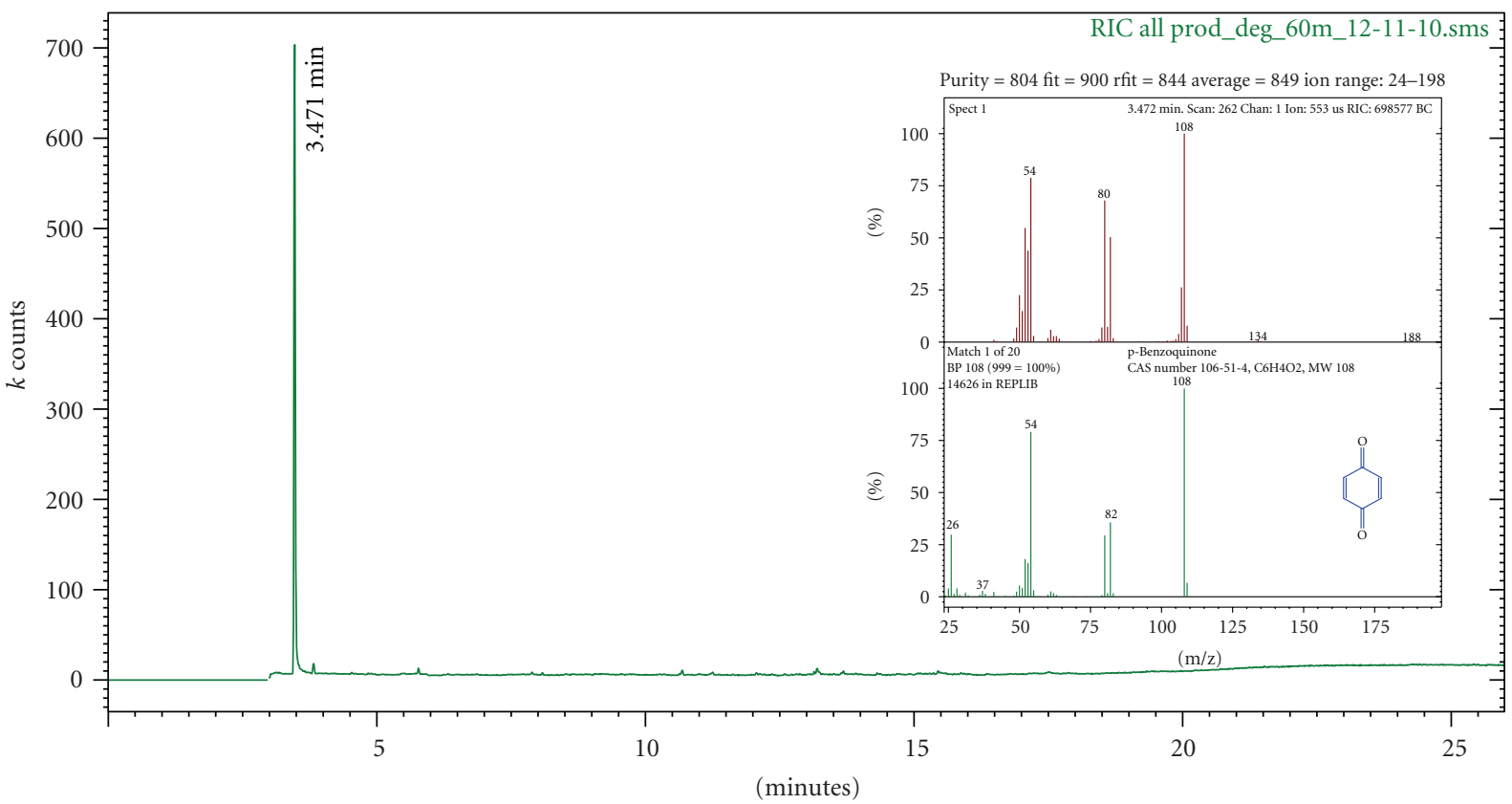

(b)

FIGURE 9: (a) GC chromatogram obtained for standard paracetamol solution in dichloromethane. $\mathrm{C}_{\text {paracetamol }}=0.2 \mathrm{mg} \mathrm{mL}^{-1}$. (b) GC chromatogram obtained for the electrochemical degradation product of paracetamol after dichloromethane extraction of the sample collected after 60 minutes of electrolysis. Inset: comparison of the mass spectra obtained experimentally with one shown by the library NIST 2005.

with the proposed online system. Figure 5 shows the decay profiles of normalized concentrations of paracetamol as a function of electrolysis time, obtained by the two methodologies here used, HPLC (off-line) and the proposed (online). In Table 2, also are show some paracetamol concentrations obtained through the two methodologies used. Based on these results, is evident a great difference between the methodologies.
The difference can be explained if we consider that the samples analyzed by the off-line method were carried out only five days after the collect. In addition, if we observed the chromatograms obtained for the degradation samples at different periods (Figure 6) a formation of a second peak at $12.6 \mathrm{~min}$ ( 2 in Figure 6 ) very close to the retention time of paracetamol at $13.2 \mathrm{~min}$ ( 1 in Figure 6), causes the calculation of peak area of paracetamol to be wrong, 


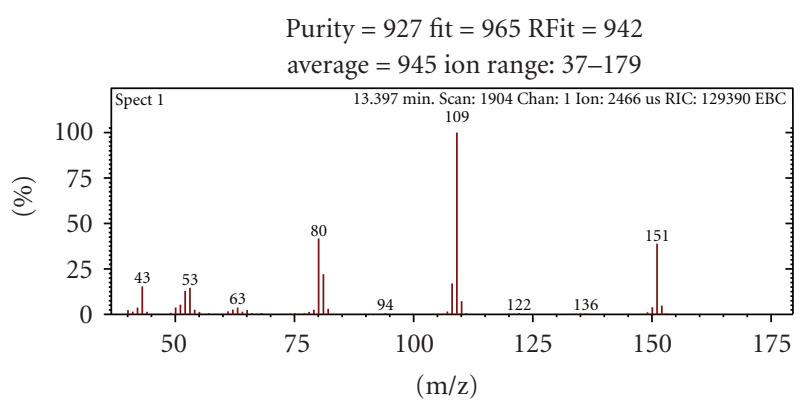

(a)

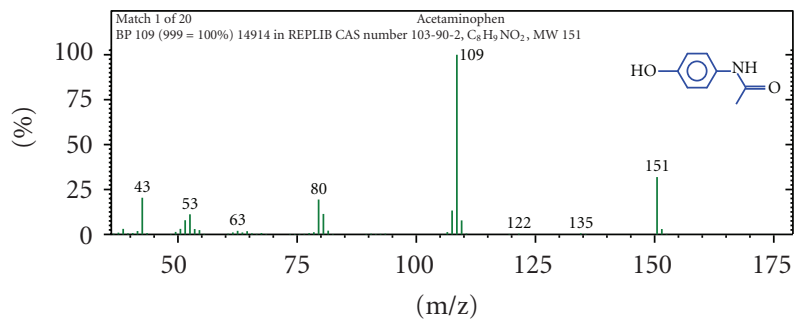

(b)

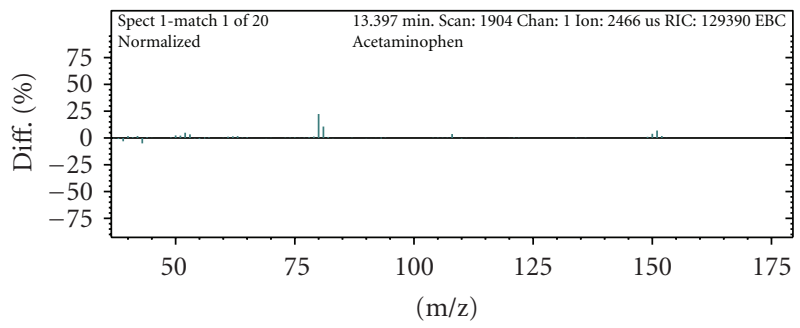

(c)

Figure 10: (a) Mass spectrum of the chromatographic peak corresponding to the retention time of $13.4 \mathrm{~min}$ of Figure 9 (a) for a paracetamol concentration of $0.2 \mathrm{mg} \mathrm{mL}^{-1}$, (b) MS recorded by the NIST library, and (c) difference of the spectra (a) and (b), attesting that the compound is paracetamol.

TABLE 2: Values of the concentration of paracetamol in the electrochemical degradation with DSA- $\mathrm{Cl}_{2}$ anode at $100 \mathrm{~A} \mathrm{~cm}^{-2}$, obtained through the method FIA with amperometric detector (biomimetic sensor) and chromatography (reference).

\begin{tabular}{lcc}
\hline \multirow{2}{*}{ Electrolysis time/min } & \multicolumn{2}{c}{$[$ Paracetamol $] / \mathrm{mol} \mathrm{L}^{-1}$} \\
& FIA/sensor & HPLC \\
\hline 0 & 0.0135 & 0.0135 \\
20 & 0.0113 & 0.0131 \\
40 & 0.0101 & 0.0131 \\
60 & 0.0081 & 0.0128 \\
80 & 0.0076 & 0.0124 \\
90 & 0.0073 & n.a. \\
120 & 0.0069 & 0.0119 \\
\hline
\end{tabular}

n.a.: not analyzed.

providing a value greater concentration and thus giving an inexact profile of the degradation.

On the other hand, it should be emphasized that the online system is not influenced by the presence of degradation product 2 (Figure 6) or others, due to the high selectivity shown by the biomimetic sensor used as the detector in the electroanalytical system $[10,12]$. At the same time, the results of electrochemical degradation of paracetamol are obtained and recorded in real-time just after the output of reactor, avoiding sample contamination and parallel reactions occur in the collected samples.

In this way, the advantages offered by this on-line system proposed to monitor degradation experiments are evident, opening a new alternative for the conventional and off-line monitoring methodologies.

3.5. Identification of Products Formed in the Paracetamol Degradation Using Hyphenated Techniques: UPLC/MS and $G C / M S$. In order to identify the degradation products of paracetamol at $100 \mathrm{~A} \mathrm{~cm}^{-2}$ and, consequently, to show the sensor selectivity used as the detector in the FIA system, was initially used the Ultra performance liquid chromatography (UPLC) coupled to mass spectrometry (Figures 7 and 8).

In Figure 7 are shown the chromatograms obtained for a standard solution of $1.0 \mathrm{mg} \mathrm{mL}^{-1}$ paracetamol (Figure 7(a)) and from samples collected at 0 min (Figure 7(b)), $30 \mathrm{~min}$ (Figure 7(c)), 60 min (Figure 7(d)), and 90 min (Figure 7(e)) of degradation. It is again possible to observe the two peaks in the degradation samples at 0.40 and 0.45 minutes (Figures $7(\mathrm{c})-7(\mathrm{e}))$. The first peak increases with electrolysis time, such expected (the degradation compound formed), and the second peak corresponds to paracetamol, as verified by, Figures $7(a), 7(b)$, and $8(b)$.

Analyzing the peak at $0.40 \mathrm{~min}$ (Figure 8(a)) using electrospray mass spectrometry in positive mode (ESI+) shows that this corresponds to the acetamide compound ([M + $\mathrm{H}]^{+}=60$ ), which is consistent with the loss of this group on the molecule of paracetamol (Scheme 1). For comparison purposes, is shown in Figure 8(b), the mass spectrum for the paracetamol (at $0.45 \mathrm{~min}$ ). Comparing both figures one can see clearly the difference in the mass spectra corresponding to each one these molecules. In this way, the results obtained by UPLC/MS suggest that acetamide is a product in the electrochemical degradation, which, being detected by liquid chromatography, causes errors in the calculation of the area, and consequently in the estimated concentration for paracetamol.

Moreover, in order to verify what would be the additional degradation product, corresponding to the remaining portion of the paracetamol molecule, experiments were performed using GC/MS, due to that in liquid chromatography was not possible to identify other molecules formed (Figures 6 and 7). Thus, using gas chromatography, after performing successive extractions in dichloromethane in the sample of $60 \mathrm{~min}$ of electrolysis, was observed a peak at the retention time of $3.471 \mathrm{~min}$ (Figure 9(b)) which is different from the retention time observed for the standard solution of paracetamol, which occurs at 13.4 min (Figure 9(a)). To identify the product that is formed, was analyzed the peak in Figure 9(b) by mass spectrometry and identified according to the library NIST 2005 as $p$-benzoquinone, such as shown in inset in Figure 9(b). Already for comparison purposes was 


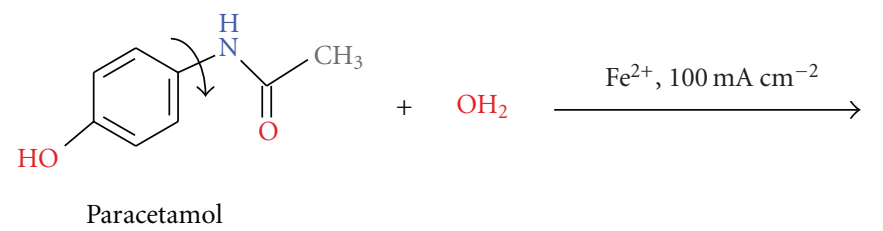<smiles>Oc1ccc(O)cc1</smiles>
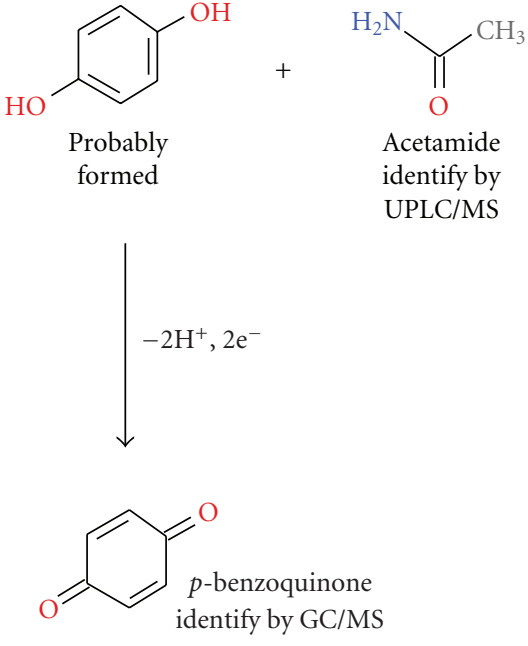

Scheme 1: Proposed route of the electrochemical degradation of paracetamol by $\mathrm{DSA}-\mathrm{Cl}_{2}$ anode, in which the degradation products were identified by hyphenated chromatographic techniques with mass spectrometry.

also analyzed the peak corresponding to paracetamol, and the corresponding mass spectrum is shown in Figure 10.

In Scheme 1 a mechanism for the degradation of the paracetamol based on experimental evidences obtained by chromatographic methods coupled to mass spectrometry is proposed. The experiments suggested the presence of $p$ benzoquinone and acetamide, on the collected samples after 60 and $90 \mathrm{~min}$ of electrolysis, respectively. The mechanism suggests that initially is promoted a cleavage of the molecule of paracetamol releasing acetamide $\left([\mathrm{M}+\mathrm{H}]^{+}=60\right)$ and probably generated the $p$-hydroquinone molecule that is immediately oxidized to $p$-benzoquinone $(\mathrm{m} / \mathrm{z}=108$, inset Figure 9(b)).

It should be emphasized that the proposed sensor does not detect the presence of acetamide or hydroquinone and p-benzoquinone during electroanalytical measurements, which makes it, in fact, an alternative tool to the traditional methods monitor the degradation processes, and that which can lead to obtain erroneous results, for example, in the profile of degradation, in calculation of some constant, and even in the current or potential of electrolysis that should be applied to obtain satisfactory results.

\section{Conclusions}

It should be emphasized that this study used as a model system the degradation of paracetamol only to demonstrate and/or evaluate the feasibility and benefits of the on-line coupling of a highly selective FIA system to a system of electrochemical degradation, which can be extended to other pollutants and other degradation processes.

The system offers the advantage of monitoring the drug concentrations in real-time, when compared to the reference method. Lastly, commonly the monitoring analyses are performed off-line and sometimes several days after that the electrolyses were performed, not reflecting the actual values obtained. In the proposed system, really reliable results are obtained once has been used a selective sensor, robust and easily constructed, that allowed obtaining a cheap, fast, and environmentally friendly method for real-time monitoring of electrochemical degradation of paracetamol.

\section{Acknowledgments}

The authors gratefully acknowledge financial support from FAPESP (Proc. 2008/00303-5). MCQO is indebted to FAPESP for a fellowship (Proc. 2008/05899-3).

\section{References}

[1] R. Bertazzoli, C. A. Rodrigues, E. J. Dallan et al., "Mass transport properties of a flow-through electrolytic reactor using a porous electrode: performance and figures of merit for $\mathrm{Pb}(\mathrm{II})$ removal," Brazilian Journal of Chemical Engineering, vol. 15, no. 4, pp. 396-405, 1998.

[2] R. L. Pelegrino, R. A. Di Iglia, C. G. Sanches, L. A. Avaca, and R. Bertazzoli, "Comparative study of commercial oxide electrodes performance in electrochemical degradation of organics in aqueous solutions," Journal of the Brazilian Chemical Society, vol. 13, no. 1, pp. 60-65, 2002.

[3] R. T. Pelegrini, R. S. Freire, N. Duran, and R. Bertazzoli, "Photoassisted electrochemical degradation of organic pollutants on a DSA type oxide electrode: process test for a phenol synthetic solution and its application for the E1 bleach Kraft mill effluent," Environmental Science and Technology, vol. 35, no. 13, pp. 2849-2853, 2001.

[4] A. Savall, "Electrochemical treatment of industrial organic effluents," Chimia, vol. 49, pp. 23-27, 1995.

[5] C. A. C. Sequeira and C. Comninellis, "Electrochemical oxidation of organic pollutants for wastewater treatment," in Environmental Oriented Electrochemistry, pp. 77-101, Elsevier, Amsterdam, The Netherlands, 1994. 
[6] L. Lipp and D. Pletcher, "The preparation and characterization of tin dioxide coated titanium electrodes," Electrochimica Acta, vol. 42, no. 7, pp. 1091-1099, 1997.

[7] B. Correa-Lozano, C. Comninellis, and A. De Battisti, "Service life of Ti/SnO2-Sb2O5 anodes," Journal of Applied Electrochemistry, vol. 27, no. 8, pp. 970-974, 1997.

[8] M. D. P. T. Sotomayor and L. T. Kubota, "Enzymeless biosensors: a novel area for the development of amperometric sensors," Quimica Nova, vol. 25, no. 1, pp. 123-128, 2002.

[9] M. D. P. T. Sotomayor, A. A. Tanaka, R. S. Freire, and L. T. Kubota, "Amperometric sensors based on biomimetic catalysts," in Encyclopedia of Sensors, vol. 1, pp. 195-210, American Scientific, Stevenson Ranch, Calif, USA, 2006.

[10] M. D. P. T. Sotomayor, A. Sigoli, M. R. V. Lanza, A. A. Tanaka, and L. T. Kubota, "Construction and application of an electrochemical sensor for paracetamol determination based on iron tetrapyridinoporphyrazine as a biomimetic catalyst of P450 enzyme," Journal of the Brazilian Chemical Society, vol. 19, no. 4, pp. 734-743, 2008.

[11] M. C. Q. Oliveira, M. R. V. Lanza, A. A. Tanaka, and M. D. P. T. Sotomayor, "Flow injection analysis of paracetamol using a biomimetic sensor as a sensitive and selective amperometric detector," Analytical Methods, vol. 2, no. 5, pp. 507-512, 2010.

[12] A. A. Tanaka, C. Fierro, D. A. Scherson, and E. Yeager, "Oxygen reduction on adsorbed iron tetrapyridinoporphyrazine," Materials Chemistry and Physics, vol. 22, no. 3-4, pp. 431-456, 1989.

[13] P. Calvo-Marzal, S. S. Rosatto, P. A. Granjeiro, H. Aoyama, and L. T. Kubota, "Electroanalytical determination of acid phosphatase activity by monitoring p-nitrophenol," Analytica Chimica Acta, vol. 441, no. 2, pp. 207-214, 2001.

[14] H. Bergamin, J. X. Medeiros, B. F. Reis, and E. A. G. Zagatto, "Solvent extraction in continuous flow injection analysis. Determination of molybdenum in plant material," Analytica Chimica Acta, vol. 101, no. 1, pp. 9-16, 1978.

[15] R. S. Rocha, A. A. G. F. Beati, J. G. Oliveira, and M. R. V. Lanza, "Evaluation of the degradation of sodium diclofenac using $\mathrm{H}$ 2O2/fenton in electrochemical reactor," Quimica Nova, vol. 32, no. 2, pp. 354-358, 2009.

[16] A. A. G. F. Beati, R. S. Rocha, J. G. Oliveira, and M. R. V. Lanza, "Study of the ranitidine degradation by $\mathrm{H} 2 \mathrm{O} 2$ electrogenerated/fenton in a electrochemical reactor with gas diffusion electrode," Quimica Nova, vol. 32, no. 1, pp. 125-130, 2009.

[17] O. De Nora, A. Nidola, G. Trisoglio, and G. Bianchi, Br. Patent no. 1399 576, 1973.

[18] L. G. P. Rezende, V. M. Do Prado, R. S. Rocha, A. A. G. F. Beati, M. D. P. T. Sotomayor, and M. R. V. Lanza, "Degradação Eletroquímica do cloranfenicol em reator de fluxo," Quimica Nova, vol. 33, no. 5, pp. 1088-1092, 2010.

[19] G. Lunn, HPLC-Methods for Pharmaceutical Analysis, Vol. 1, John Wiley \& Sons, New York, NY, USA, 2000.

[20] P. Atkins and L. Jones, "Principios de Química: Questionando a vida e o meio ambiente, traduction for Bookman," Porto Alegre, pp. 654, 2001. 


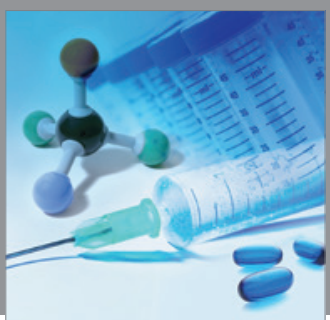

International Journal of

Medicinal Chemistry

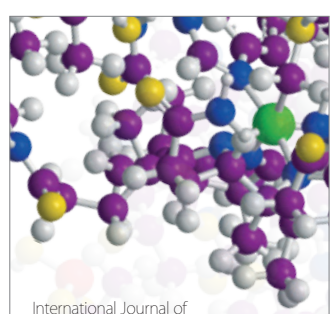

Carbohydrate Chemistry

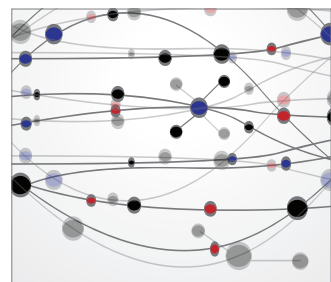

The Scientific World Journal
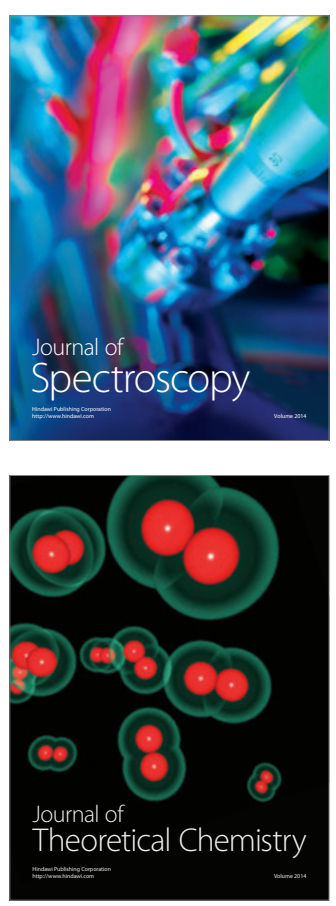
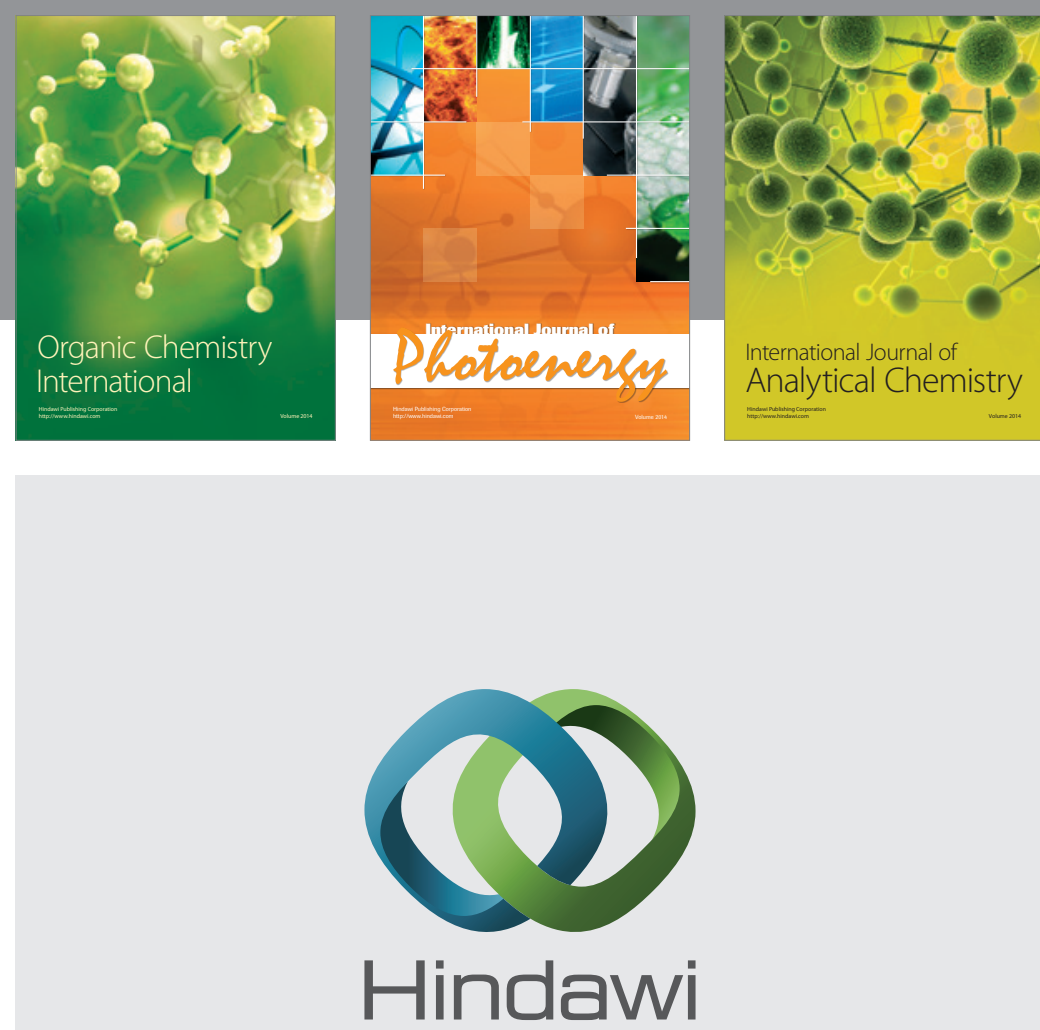

Submit your manuscripts at

http://www.hindawi.com
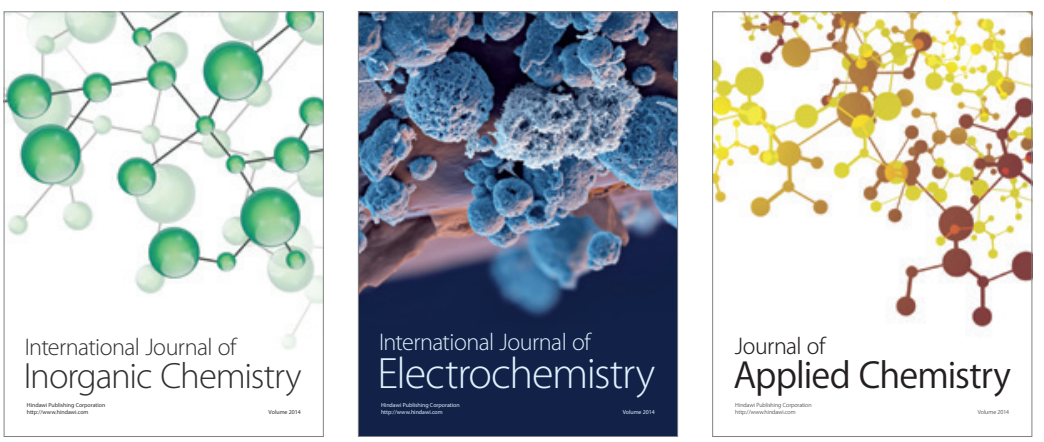

Journal of

Applied Chemistry
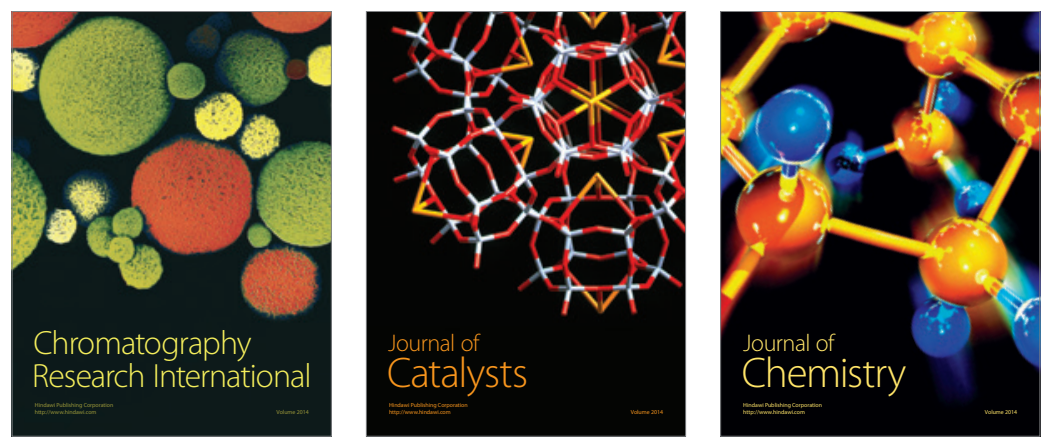
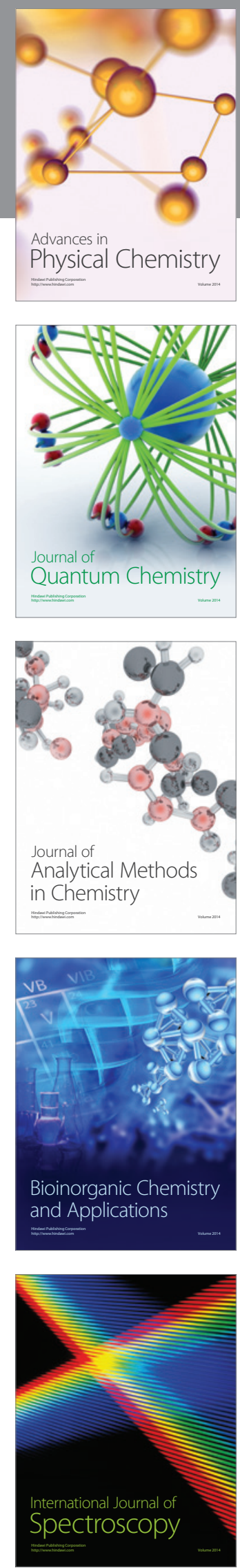